\title{
Childhood lasts a lifetime
}

\author{
F. Benjamin'
}

\section{Key points}

Highlights the epidemic of child tooth decay in the UK and extreme oral health inequalities.

In this article I discuss oral health in the UK and how this affects health inequalities. As co-Chair of the All-Party Parliamentary Group for Fit and Healthy Childhood, I believe it is important to the future of children's dental health that more dental schemes are set up across the whole of the UK and that as a society we campaign for better children's oral health.

It has been 42 years since I started taking my Play School babies through the round, square and arched windows of the much loved BBC television children's series Play School. I loved those days, and it was then that I first became a passionate advocate for children, speaking out for them and for their wellbeing and their right to a healthy and happy childhood. Over the past four decades I have campaigned persistently on behalf of children, and I am doing so more than ever now that I am in the House of Lords, because, as I always say, 'childhood lasts a lifetime'.

A child's early years are crucial to her or his long-term mental, physical and emotional wellbeing. So it's important to remember that everything we do affects children; how we treat them, how we speak to them, what we feed them, how we teach them to take care of their bodies. All of this matters to help children to develop into fit and healthy adults.

As co-Chair of the All-Party Parliamentary Group for Fit and Healthy Childhood, over the years we have looked at many issues affecting kids' lives, from obesity to mental health. And I have been delighted to help bring into the spotlight a crucial aspect of children's health

'Liberal Democrat Life Peer, co-Chair of the All-Party Parliamentary Group for Fit and Healthy Childhood Correspondence to: Baroness Floella Benjamin OBE (via the BDA Press Office)

Email: Anna.Wojnilko@bda.org

Refereed Paper. Accepted 31 March 2018

DOI: $10.1038 /$ sj.bdj.2018.271 and wellbeing that is all too often overlooked - and that's oral health.

Oral health is an issue that blights the lives of millions of children in this country, and one we can no longer afford to overlook. I am thrilled to see dental and oral health organisations making an effort to try and put the need to improve children's oral health smack bang on the government's and policymakers' agendas.

The UK is seeing an epidemic of child tooth decay, with one in four children suffering from this disease by the time they are five, and tooth extraction is the number one reason young children are admitted to hospital across the UK. This sounds like a Dickensian news report doesn't it? According to the latest statistics 170 children undergo general anaesthesia every day to have multiple decayed teeth removed. That is simply unacceptable.

Poor oral health is a symptom - but also a driver - of the deepening health inequalities in our country. There are huge variations in rates of decay, with children in the poorer parts of the country seven times more likely to be affected than their peers in more affluent areas. Yet when we discuss the challenges around children's health, teeth and gums are often forgotten, with dentistry often regarded as the 'Cinderella' service in our NHS. This is a huge mistake not only because poor dental health causes children unnecessary pain and distress, and costs the NHS millions of pounds, but also because $90 \%$ of tooth decay is preventable which simply means things don't need to be like this.
Importantly, oral health also has a much wider and deeper impact on kids' overall health, their wellbeing, confidence, mental health and school life. It's crucial to understand what a big difference improving oral health can make to a child. A bright smile really can bode well for a child's future; improving oral health isn't just about preventing pain, it can also have a much bigger effect on a child's self-esteem, school performance and long-term oral health.

A child's smile is a big part of how they view themselves - if they are proud of it they will be more confident, and more likely to socialise and have fun with others. I always say 'keep smiling, because winners smile!' and I want all children to feel like winners! But sadly we know from the most recent Child Dental Health Survey ${ }^{1}$ that $35 \%$ of 12 -year-olds were embarrassed to smile or laugh because of the condition of their teeth and mouth - just imagine the change we would see in these children if they were happy with their smile.

Oral health can also affect how children do at school - research by Public Health England has found that in North West England, 26\% of children who were in hospital for a tooth extraction had missed days at school because of dental pain or infection. On average these children missed three days of school due to dental problems, but some were absent for up to 15 days.

This simply shouldn't be happening in this day and age, in today's technologically advanced society. If these children weren't having to take 
time off for treatment, and weren't losing sleep because of dental pain, they would undoubtedly be able to concentrate more at school and become better and happier learners. We also know that oral health problems in childhood can continue to have an impact when they grow up, as children who have high levels of disease in primary teeth have an increased risk of disease in their permanent teeth.

But if a child's first experience of the dentist is a scary or unpleasant one, such as having a tooth extraction, it may also make them reluctant to go back, meaning oral health problems later in life will not get picked up until it is too late.

Ensuring children lose their fear of the dentist and get all the benefits that a bright and healthy smile can bring isn't impossible - but it does require us to work together to tackle poor oral health. Fortunately, while the challenge is big, the solutions are not complicated. Crucially, what we need stronger action on is the ' $\mathrm{S}$ ' word - sugar! Because an average 5 -year-old eats their bodyweight in sugar every year ${ }^{2}$, and with sugar being the number one cause of tooth decay, this is the common sense place to start.

According to the British Dental Association, teenagers get $40 \%$ of their added sugars from soft drinks, and so the sector has greeted the Soft Drinks Industry Levy, which came into force in April this year, as a welcome first step in the right direction. But it is not a silver bullet that will on its own tackle the massive challenge of poor oral health that we are facing. We need much bolder measures, with a levy covering a wider range of sugary food and drinks, as well as stricter controls around marketing and price promotions involving high sugar products, and clearer labelling and information, as well as education to help parents make better choices. The Government should also look at the possibility of investing part of the proceeds from the sugar levy into children's oral health initiatives.

As it stands England is falling behind in terms of oral health education and decay prevention. Scotland and Wales have been leading the way with their innovative early intervention schemes, ChildSmile and Designed2Smile. Simple solutions such as supervised toothbrushing in schools and nurseries, application of fluoride varnish and regular visits to the dentist have led to unprecedented improvements in oral health outcomes of Scottish and Welsh children. Kids in England deserve nothing less.

In 2017 NHS England launched the 'Starting Well' programme, which aims to reduce oral health inequalities and improve oral health in children under the age of five years. And the new British Society of Paediatric Dentistry's 'Dental Checks by 1' initiative aims to ensure parents take babies to see a dentist as soon as their first teeth come through, usually around six months and definitely before their first birthday.

However, neither of the schemes has received any new government money and I am very concerned that 'Starting Well' is limited to just 13 local authorities in England, with the Ministers admitting that the funding for this scheme would be provided within existing dental spend?. This is cause for concern and one I plan to raise in the House of Lords.

The last meeting of my All Party Parliamentary Group on a Fit and Healthy Childhood, we focused on the topic of 'Why children's oral health is everybody's business', and the message came out loud and clear, that to tackle a problem like child tooth decay everyone needs to work together and pull in the same direction.

Dentists of course have a crucial role to play, but they can't turn this around on their own. Health visitors, midwives, community nurses, early years' workers, pharmacists and others all have opportunities to engage children and parents, and it is essential that they all provide consistent and accurate advice about maintaining good oral health. The Faculty of Dental Surgery, among others, has been calling for oral health to be included in health workers' training and professional development. This isn't about training health visitors to be dentists - it's to enable them to identify signs that a child may have an oral health problem and signpost them to further help. The Government needs to ensure that the public health workforce is appropriately trained about the importance of oral health, and how they can support children and parents in maintaining it.

Another important element that also needs to be addressed is the variations in dental access across the country. It was reported in the media last year the difficulties that those in some areas were having in accessing treatment; areas such as Cornwall where more than 14,000 people were apparently on a waiting list to register with an NHS dental practice. So while NHS dental treatment is free for children, if parents themselves do not go to the dentist this can be a significant barrier to children's attendance. So there needs to be action to solve these problems and deal with them swiftly.

Public Health England has been proactive on child oral health, giving direction on the range of evidence-based oral health activities that local authorities should be implementing, the effectiveness of which has been demonstrated in Scotland's Childsmile initiative. However, there appears to be limited national momentum to ensure all local authorities are fulfilling their responsibility for child oral health and prevention. So again the Government needs to ensure that all English councils are actively implementing Public Health England's recommendations - such as having sustained programmes for toothbrush and toothpaste distribution, community-based fluoride varnish programmes and supervised tooth brushing in nurseries - at local level. Government also needs to improve oral health education so that parents and children understand the impact of sugar on teeth and the importance of a good oral hygiene regime.

I do welcome the efforts made to make parents aware of the importance of taking their babies to the dentist before their first birthday, but we need to invest more into NHS dentistry to make this practical. Trying to spread shrinking resources ever thinner is not the answer.

Four in ten children did not see an NHS dentist in the last 12 months, even though such check-ups are free for under-18s and should ideally take place every six months. If we want good oral health for our children, we need to ensure dental services are appropriately commissioned and funded. We must also ensure that the new dental contract, which is currently being developed, rewards dentists for keeping patients healthy, and not - as is currently the case - for the number of procedures they perform, so as to incentivise a more preventative approach.

Another important point is that we should look at ways to encourage all local authorities to consider introducing fluoride into their water supply because the evidence is clear that water fluoridation is a safe and effective measure to help people improve oral health, particularly in children. According to PHE, for every $£ 1$ invested into fluoridation there will be a $£ 12$ saving after five years and almost $£ 22$ for every $£ 1$ after ten years.... This is common sense! But many local authorities simply can't afford to make the initial investment. So we should look into how the Government could make it easier for them to do so if a council felt fluoridation was an appropriate measure for their area.

The trouble with all this is that funding for dentistry has been falling, despite the increase in need as our population grows and we all live for longer and keep our teeth for longer. 
According to the BDA calculations, back in 2006 the Government set aside $£ 35$ per head to cover dental care for every adult and child in England. This amount, however, has fallen by $£ 7.50$ per head in real terms in the last decade, pushing NHS dentistry into a state of chronic underfunding.

But we cannot allow austerity to be an excuse for us not to do whatever we can to reverse and help solve this scandalous situation the country finds itself in. A situation that is affecting our children's oral health and wellbeing. Everyone has a role to play in improving children's oral health, including lobbying, and campaigning, which I personally pledge to continue to do.

I am an optimist, I do see light at the end of the tunnel. This is what keeps me going. I truly believe the good news is that child tooth decay is a problem that we can and will solve if we work together and get some simple things right, to prevent the appalling suffering, anguish, loss of school time, depression and sheer unnecessary pain our children are having to go through today. Children's oral health really is everybody's business. So let's do all we can to give every child a brighter smile and the brighter, healthier future that comes with it. Together we are going to win this battle!

1. Children's Dental Health Survey 2013. Executive Summary, England, Wales and Northern Ireland. Available online at https://digital.nhs.uk/media/26567/ CDHS-2013-Executive-Summary/Any/CDHS2013-Executive-Summary (accessed 13 April 2018).

2. Public Health England. 5 year olds eat and drink their body weight in sugar every year. Press Release. 4 January 2016. Available online at https://www.gov.uk/ government/news/5-year-olds-eat-and-drink-their-bodyweight-in-sugar-every-year (accessed 13 April 2018). 